SUPPORTING INFORMATION

For

\title{
Ga-Supported MFI Zeolites Synthesized Using Carbon Nanotubes Containing Gallium Oxide Nanoparticles on Exterior Walls and in Interior Channels as Hard Templates for Methanol Aromatization
}

Ching-Jung Chang, ${ }^{\mathrm{a}}$ Chin-Han Chen, ${ }^{\mathrm{a}}$ Jyh-Fu Lee, ${ }^{\mathrm{b}}$ Tawan Sooknoi, ${ }^{\mathrm{c}, \mathrm{d}}$ and Yu-Chuan $\operatorname{Lin}^{\mathrm{a}, *}$

a Department of Chemical Engineering, 1 University Road, National Cheng Kung University, Tainan 70101, Taiwan

${ }^{b}$ National Synchrotron Radiation Research Center, 101 Hsin-Ann Road, Hsinchu 30076, Taiwan

${ }^{c}$ Department of Chemistry, Faculty of Science, King Mongkut's Institute of Technology Ladkrabang, Bangkok, 10520, Thailand

${ }^{\mathrm{d}}$ Catalytic Chemistry Research Unit, Faculty of Science, King Mongkut's Institute of Technology Ladkrabang, Bangkok 10520, Thailand

*Corresponding author's email: yclin768@mail.ncku.edu.tw 


\section{Description of the SAC method}

Designated amounts of aluminum nitrate and tetrapropylammonium hydroxide (TPAOH, Alfa Aesar, 40\% aqueous solution) were completely dissolved in deionized water, following by adding tetraethyl orthosilicate (TEOS, Acros 98\%) dropwise into the solution to form a transparent mixture. The composition of the mixture was 1.5 Al:60 Si:16 TPAOH:5400 $\mathrm{H}_{2} \mathrm{O}$. After vigorous agitation for $24 \mathrm{~h}$, the yielded sol was dried in an oven at $80{ }^{\circ} \mathrm{C}$ for $20 \mathrm{~h}$. The resultant powder was collected and placed into a $4 \mathrm{~mL}$ PTFE-made cup. The cup was then transfer into a $100 \mathrm{~mL}$ autoclave, which was prefilled with $5 \mathrm{~mL}$ of $25 \%$ aqueous ammonia. ${ }^{1}$ The autoclave was then sealed and moved to an oven to be heated at $175^{\circ} \mathrm{C}$ for $24 \mathrm{~h}$. The resultant solid was washed with deionized water several times until the $\mathrm{pH}$ value of the filtrate was at $\sim 7$. The paste was dried at $60{ }^{\circ} \mathrm{C}$ overnight and calcined at $600{ }^{\circ} \mathrm{C}$ for $20 \mathrm{~h}$ to obtain ZSM-5 catalysts. 


\section{Physicochemical characterizations}

Powder X-ray diffraction (XRD) analysis was performed on a diffractometer (Rigaku D/Max-IIB) at $40 \mathrm{kV}$ and $40 \mathrm{~mA}$ with Ni-filtered $\mathrm{Cu} \mathrm{K} \alpha$ radiation.

The morphology of tested catalyst was observed by a cold field emission scanning electron microscope (SEM, Hitachi SU8010) and high-resolution transmission electron microscope (HR-TEM, JEOL JEM-2010).

An inductively coupled plasma-atomic emission spectrometer (ICP-AES, Kontron S-35) was used to quantify the compositions of Si, Al, and Ga.

$\mathrm{N}_{2}$ physisorprion measurements were carried out using a 3Flex Surface Analyzer (Micromeritics USA). Prior to the measurement, approximately $80 \mathrm{mg}$ sample was degassed at $300{ }^{\circ} \mathrm{C}$ in vacuum for $3 \mathrm{~h}$ (ramp rate $1{ }^{\circ} \mathrm{C} / \mathrm{min}$ ). The Brunauer-EmmettTeller (BET) method in the relative pressure range of $0.01-0.1$ was used to estimate the equivalent surface area $\left(\mathrm{S}_{\mathrm{BET}}\right)$. The $t$-plot method was used to access microporosities of $\mathrm{HZ}$ and $\mathrm{Ga} / \mathrm{HZ}$. Because of a possible underestimation of microporosity of hierarchical samples by using the t-plot method, an abacus for $t$-plot analysis correction. ${ }^{2}$

The ${ }^{27} \mathrm{Al}$ and ${ }^{29} \mathrm{Si}$ magic angle spinning nuclear magnetic resonance (MAS NMR, Bruker Avance 400) spectra were obtained at the spinning speeds of 10 and $8 \mathrm{kHz}$ in the magnetic field of $9.4 \mathrm{~T}$. The ${ }^{27} \mathrm{Al}$ spectra were recorded using a $3 \mu$ s single-pulse time $\left(90^{\circ}\right)$ with a $4 \mathrm{~s}$ acquisition delay. For the ${ }^{29} \mathrm{Si}$ spectra, a $3 \mu$ s single-pulse time and a $60 \mathrm{~s}$ delay were used. The NMR spectra were normalized to the weight of catalyst.

Ga $K$-edge X-ray absorption data were recorded in transmission mode at beamline TLS-17C1 of the National Synchrotron Radiation Research Center, Taiwan. The edge energy of each spectrum was set to $10375.1 \mathrm{eV}$ by using $\beta-\mathrm{Ga}_{2} \mathrm{O}_{3}$ as the reference. Proper amount of sample was packed and sealed inside Scotch tapes for measurement. All spectra were acquired at ambient conditions.

Normalization of XANES was conducted by using Athena software, and curve-fitting of EXAFS was performed by using the Artemis software. The Athena and Artemis software are ver. 0.9.26 included in the Demeter package. ${ }^{3}$ EXAFS spectra $\left(k^{3}\right.$-weighted) were Fourier transformed and fitted to various coordination shells in the k-range of $3.0-12.4 \AA^{-1}$. The amplitude reduction factors $\left(\mathrm{S}_{0}^{2}\right)$ of the Ga-O shell (0.95) was acquired by fitting the first shell of the EXAFS spectrum of 
$\beta-\mathrm{Ga}_{2} \mathrm{O}_{3}$.

Fourier-transform infrared spectra of pyridine-adsorbed (Py-IR) samples were recorded by using a Thermo Scientific Nicolet iS50 spectrometer and an in situ quartz cell. The dehydrated sample was treated at $400^{\circ} \mathrm{C}$ for $3 \mathrm{~h}$ under a vacuum of $1.2 \times 10^{-}$ ${ }^{3} \mathrm{~Pa}$. The dehydrated sample was then cooled to $30^{\circ} \mathrm{C}$ and exposed to pyridine vapor. Before recording the spectrum, excess pyridine was removed at $350{ }^{\circ} \mathrm{C}$ under a vacuum of $1.2 \times 10^{-3} \mathrm{~Pa}$.

The tests of temperature-programmed reduction of $\mathrm{H}_{2}\left(\mathrm{H}_{2}-\mathrm{TPR}\right)$, temperature-programmed desorption of $\mathrm{NH}_{3}\left(\mathrm{NH}_{3}-\mathrm{TPD}\right)$, and isopropylamine (IPA)-TPD were performed by using a chemisorption analyzer (AutoChem-II, Micromeritics), and the signals were recorded by a thermal conductivity detector (TCD) or a quadrupole mass gas analysis system (ThermoStar GSD 320 T, Pfeiffer Vacuum). Reference gases including $10 \% \mathrm{H}_{2} / \mathrm{He}, \quad 10 \% \mathrm{NH}_{3} / \mathrm{He}$, and $10 \%$ propylene/Ar, were used to calibrate the MS signals of $\mathrm{m} / \mathrm{e}=2,17$, and 41 , respectively. The response factor of TCD was obtained by using known pulses of 10 $\% \mathrm{NH}_{3} / \mathrm{He}$ as the standard for the analysis of $\mathrm{NH}_{3}$-TPD. For IPA-TPD, the sample was pretreated in a He stream $(100 \mathrm{~mL} / \mathrm{min})$ with a heating rate of $10{ }^{\circ} \mathrm{C} / \mathrm{min}$ from 30 ${ }^{\circ} \mathrm{C}$ to $500{ }^{\circ} \mathrm{C}$ and kept isotherm for $1 \mathrm{~h}$. For $\mathrm{NH}_{3}-\mathrm{TPD}$, the sample was pretreated using the above-mentioned program, followed by purging the pretreated sample in a $10 \% \mathrm{NH}_{3} / \mathrm{He}$ stream at $100{ }^{\circ} \mathrm{C}$ for $1 \mathrm{~h}$ to achieve saturated adsorption. Commercial HZSM-5 (Zeolyst CBV 8014, Si/Al $=40$ ), possessing a total acidity of $420 \mu \mathrm{mol} / \mathrm{g}^{4}$ and a concentration of Brønsted acid of $335 \mu \mathrm{mol} / \mathrm{g}^{5}$ was used as the standard for the estimations of crystallinity and acidity. 


\section{Activity Evaluation}

A continuous flow fixed-bed reactor connected to an online gas chromatograph (GC) was used as the activity evaluation system. The contact time was set at 0.42 and $0.20 \mathrm{~kg}_{\text {cat }} \cdot \mathrm{min} / \mathrm{mol}\left(\mathrm{WHSV}=4.6 \mathrm{~h}^{-1}\right.$ ), and reaction temperatures were set at $500{ }^{\circ} \mathrm{C}$ under atmospheric pressure. In a typical run, $0.1 \mathrm{~g}$ of sample was used. The sample was pretreated in a $\mathrm{N}_{2}$ stream $(60 \mathrm{~mL} / \mathrm{min})$ at $500{ }^{\circ} \mathrm{C}$ for $2 \mathrm{~h}$ for activation. Methanol was introduced by a syringe pump with an injection rate of $0.9 \mathrm{~mL} / \mathrm{h}$. The initial product performances were the averaged results of the first three data points after stabilization.

For stability test, the regeneration of each used catalyst was performed at $600{ }^{\circ} \mathrm{C}$ in an air stream $(100 \mathrm{~mL} / \mathrm{min})$ for $3 \mathrm{~h}$ in the same fixed-bed system after the time-on stream test of its fresh form.

The definitions of conversion and selectivity were defined as below:

Conversion of reactnat $(\%)=\left(\frac{\mathrm{CH}_{3} \mathrm{OH}_{\text {feed }}-2 \times \mathrm{DME}_{\text {exhaust }}}{\mathrm{CH}_{3} \mathrm{OH}_{\text {feed }}}\right) \times 100 \%$

Selectivity of product $X_{i}(\%)=\left(\frac{\text { Number of } C \text { atoms of product } X_{i}}{\text { Sum of } C \text { atoms in hydrocarbon products }}\right) \times 100 \%$ 


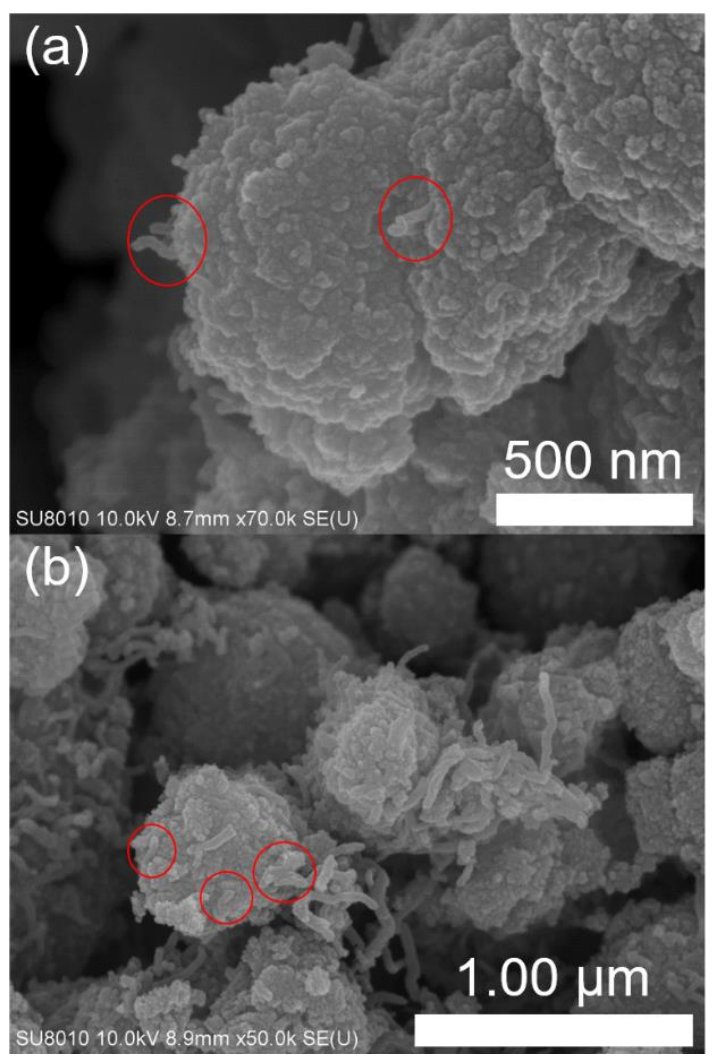

Figure S1. SEM images of the precursors of (a) $\mathrm{Ga}_{\text {out }} \mathrm{CNT}-\mathrm{HZ}$ and (b) $\mathrm{Ga}_{\text {in }} \mathrm{CNT}-\mathrm{HZ}$ before calcination 

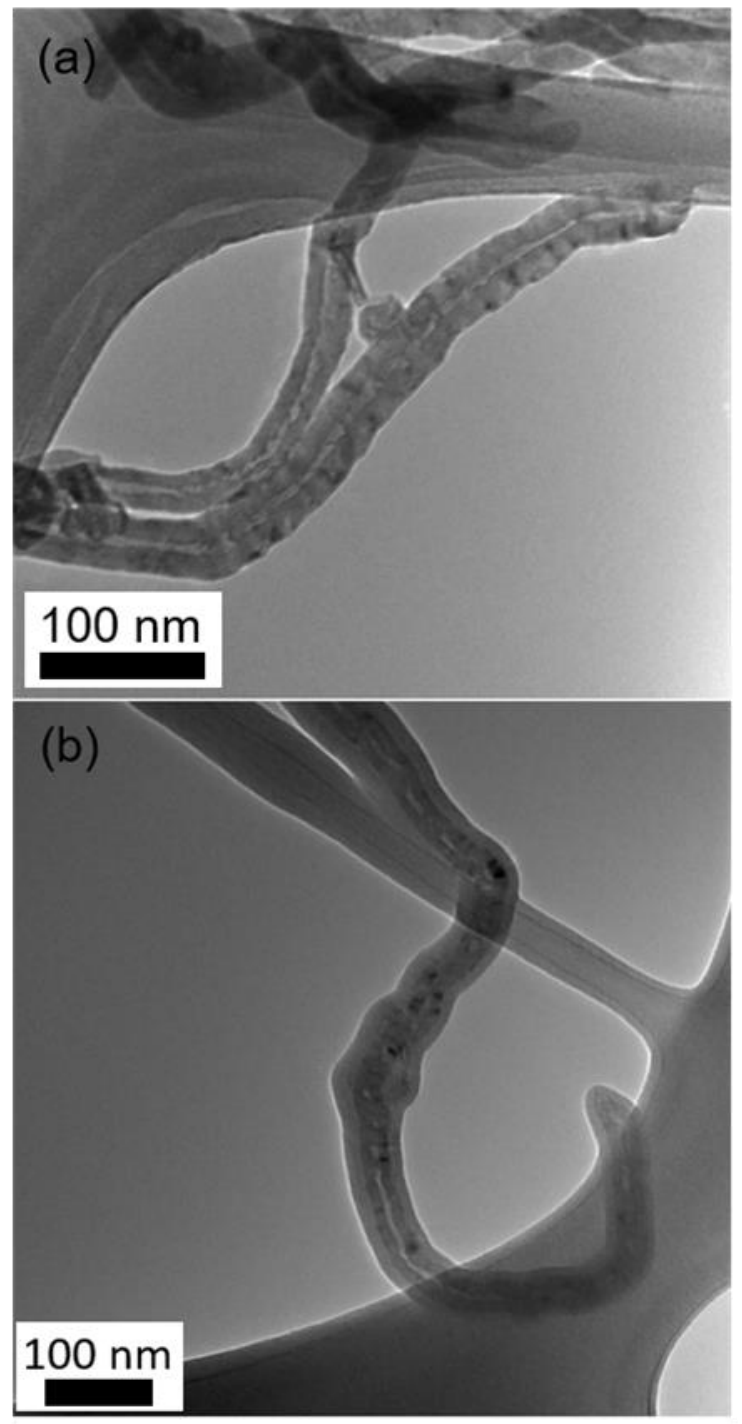

Figure S2. TEM images of the precursors of (a) $\mathrm{Ga}_{\text {out }} \mathrm{CNTs}$ and (b) $\mathrm{Ga}_{\text {in }} \mathrm{CNTs}$ 
(a)

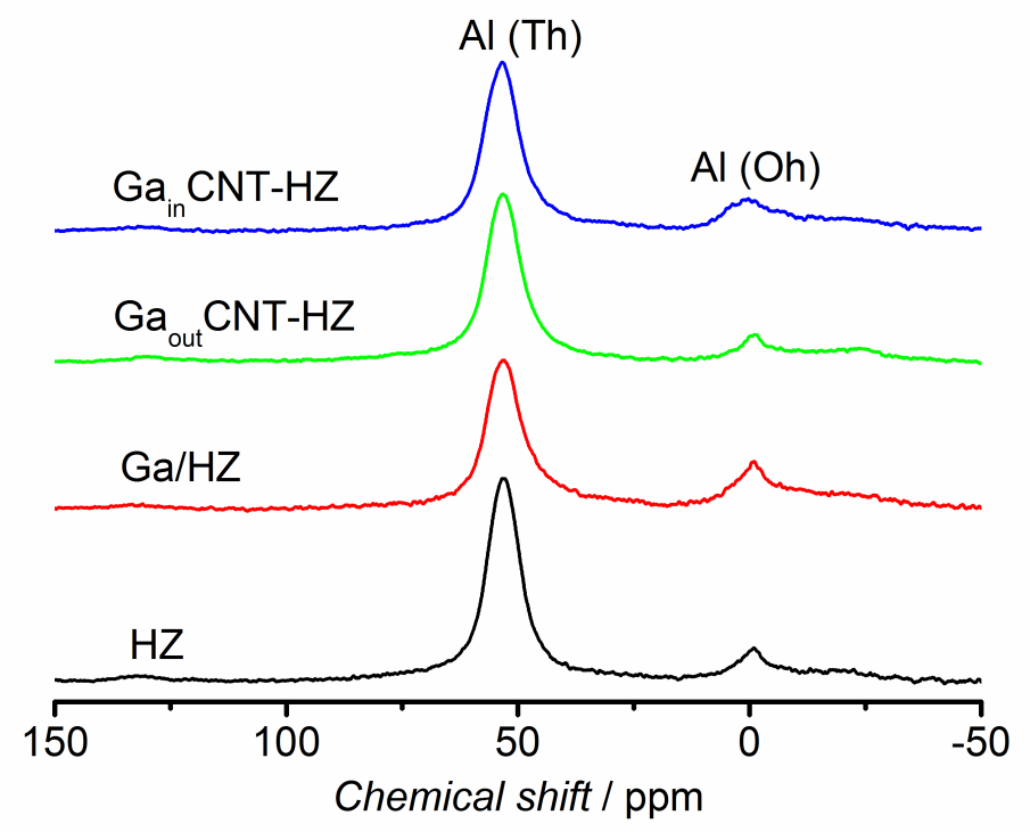

(b)

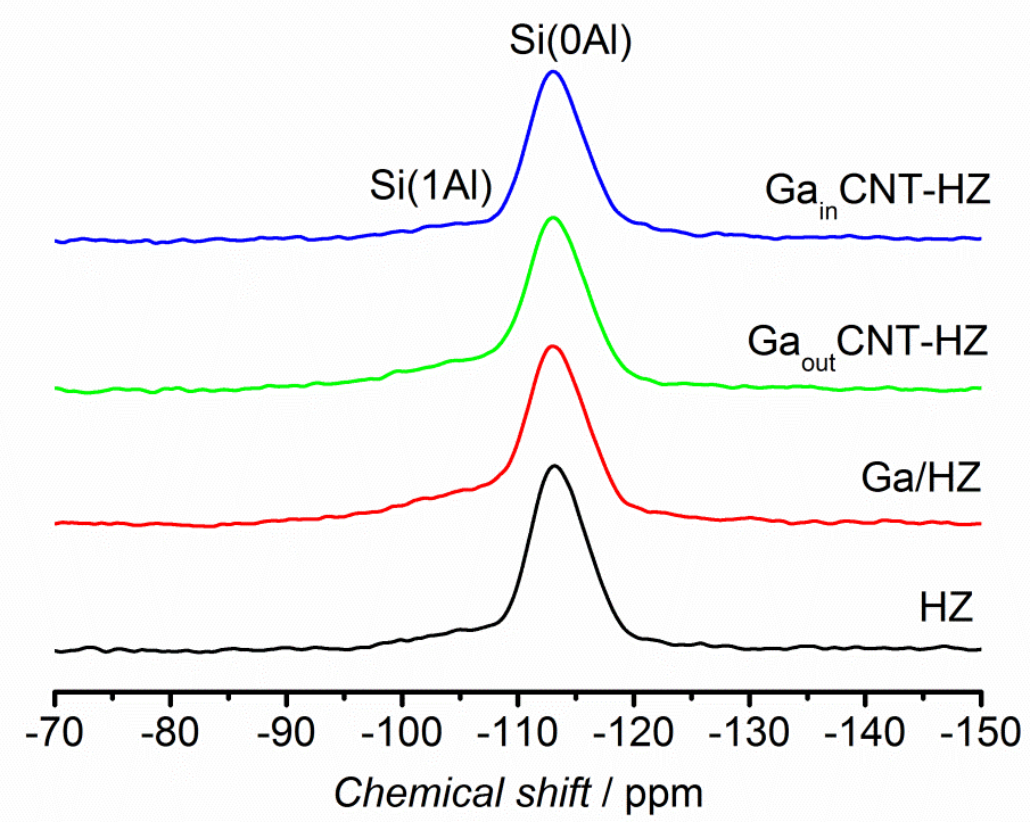

Figure S3. (a) ${ }^{27} \mathrm{Al}$ and (b) ${ }^{29} \mathrm{Si}$ MAS NMR spectra of tested catalysts. 


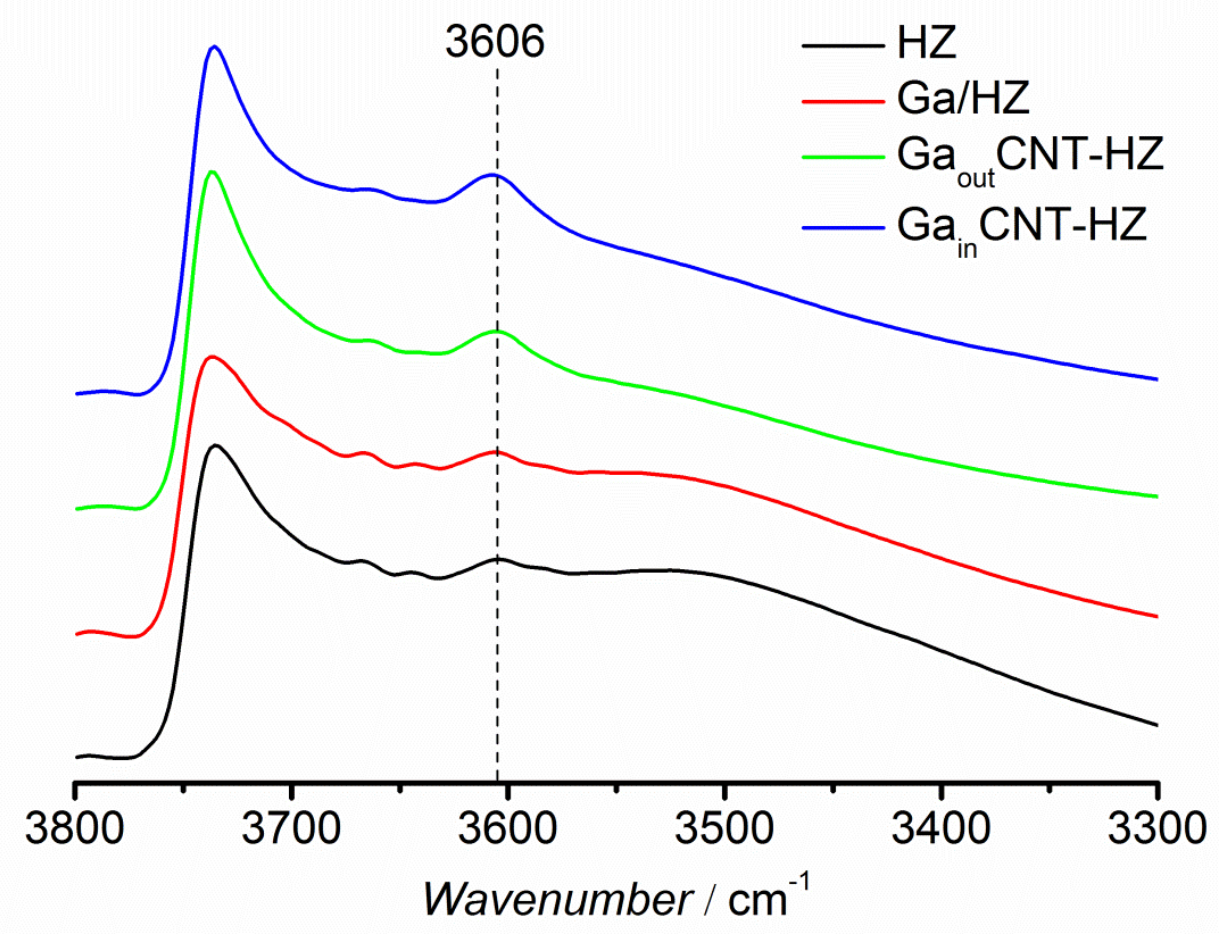

Figure S4. The IR spectra of dehydrated catalysts in the Si-OH region. 

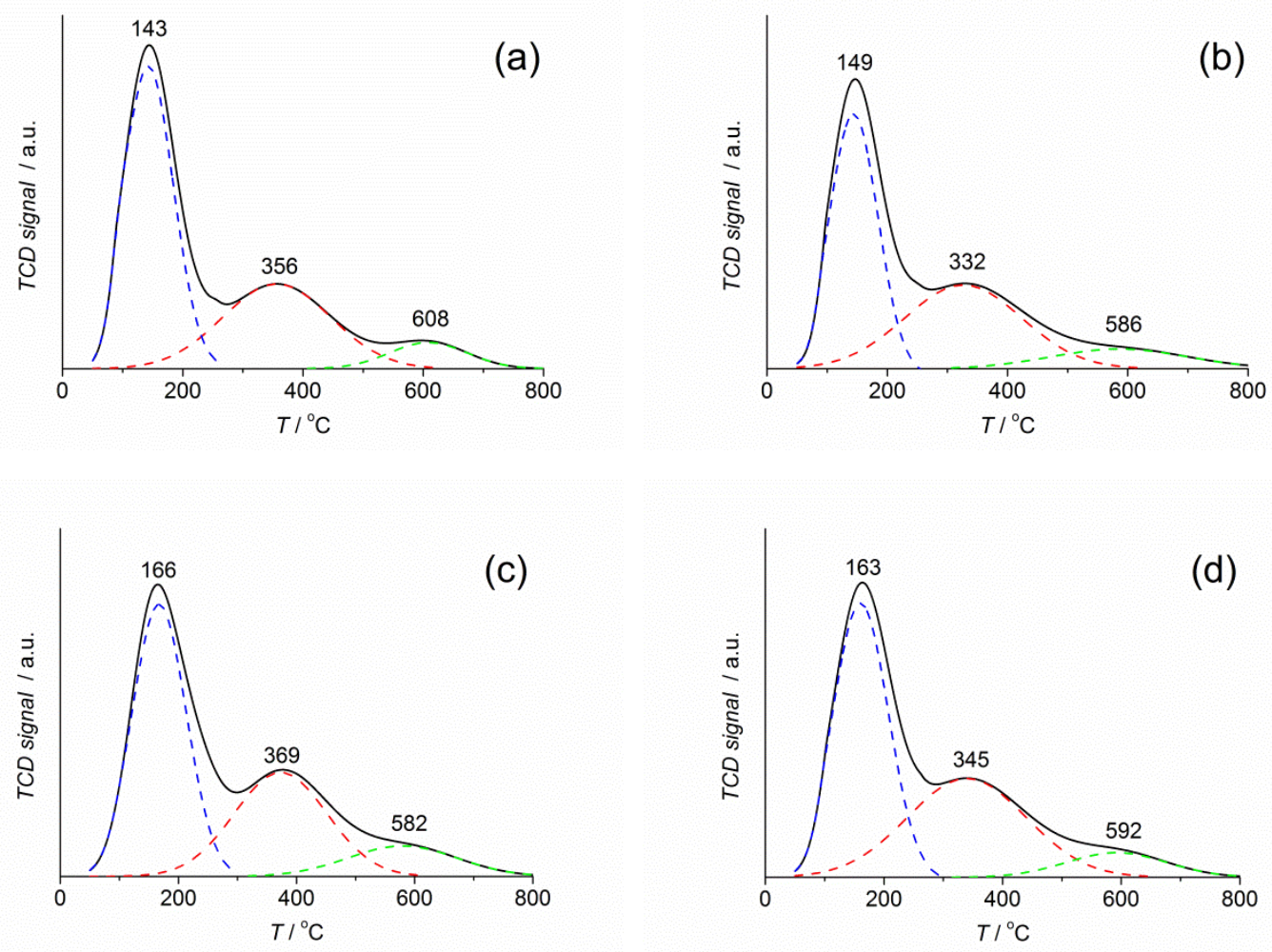

Figure S5. $\mathrm{NH}_{3}-\mathrm{TPD}$ profiles of (a) $\mathrm{HZ}$, (b) $\mathrm{Ga} / \mathrm{HZ}$, (c) $\mathrm{Ga}_{\text {out }} \mathrm{CNT}-\mathrm{HZ}$, and (d) $\mathrm{Ga}_{\text {in }} \mathrm{CNT}-\mathrm{HZ}$ 


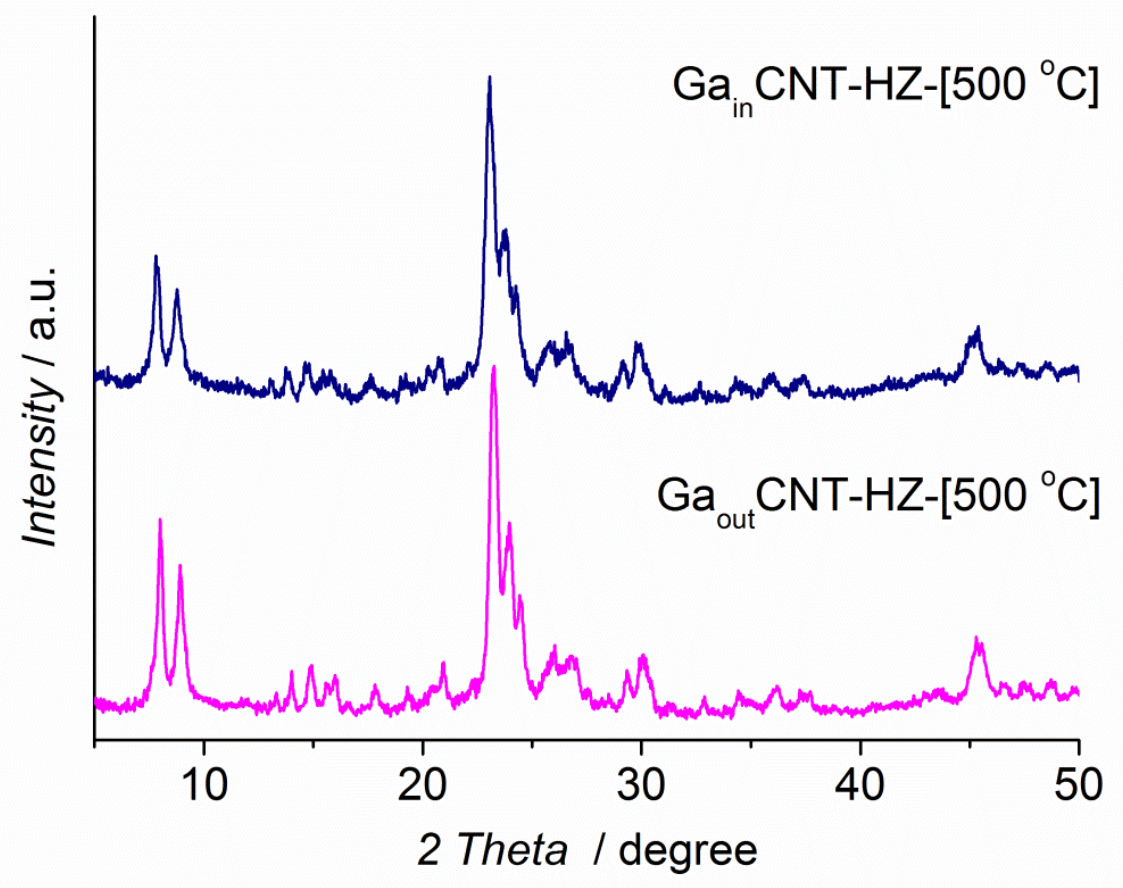

Figure S6. XRD patterns of (a) Ga $a_{\text {out }} \mathrm{CNT}-\mathrm{HZ}-\left[500^{\circ} \mathrm{C}\right]$ and (b) $\mathrm{Ga}_{\text {in }} \mathrm{CNT}-\mathrm{HZ}-[500$ $\left.{ }^{\circ} \mathrm{C}\right]$ 
(a)

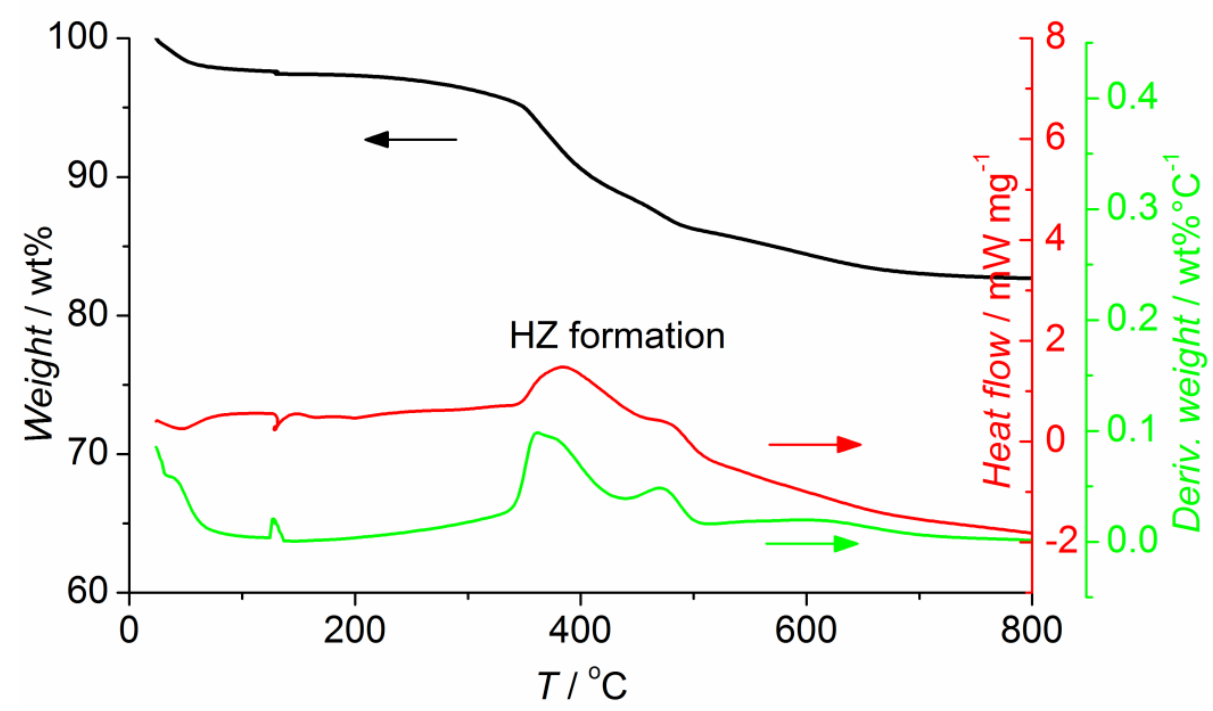

(b)

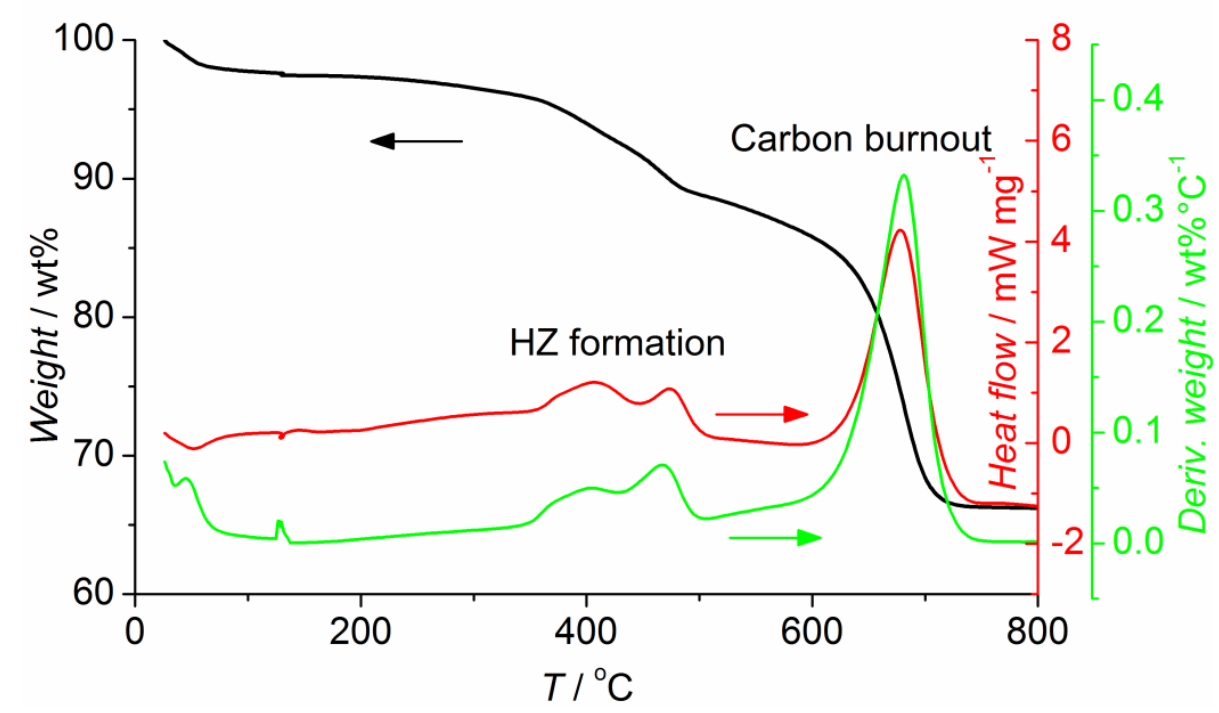

(c)

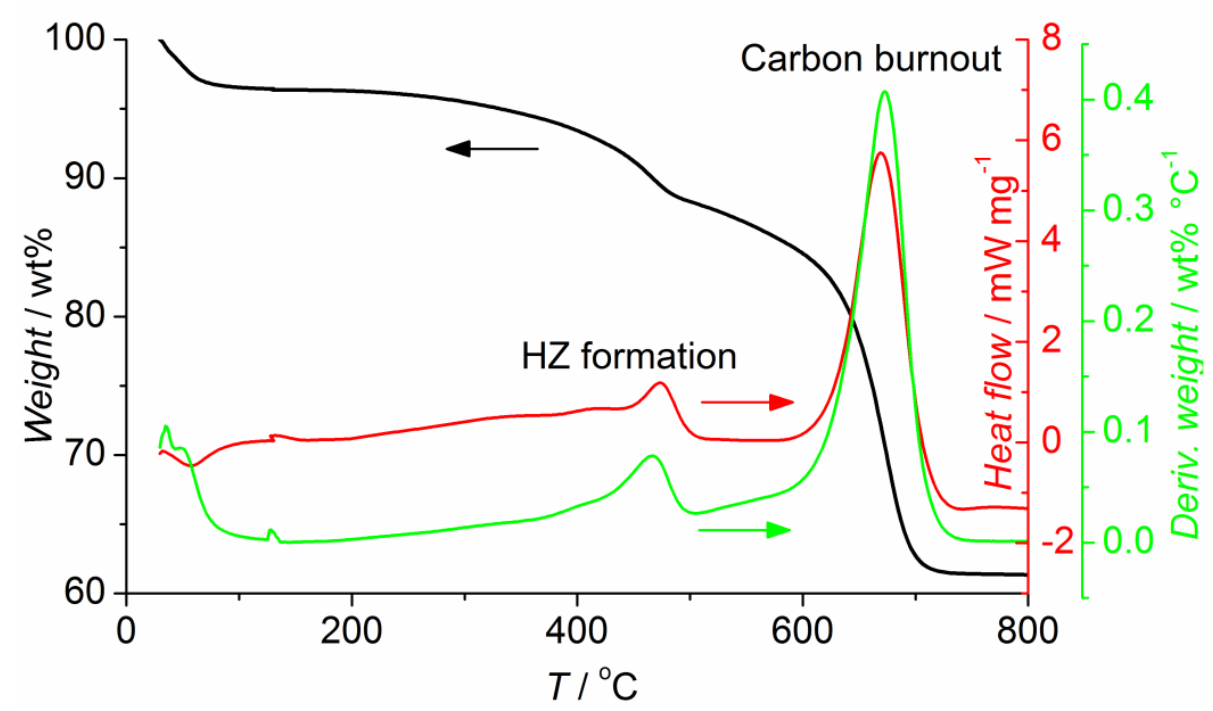

Figure S7. Thermal analysis of precursors of (a) HZ, (b) Ga ${ }_{\text {out }} \mathrm{CNT}-\mathrm{HZ}$, and (d) Ga ${ }_{i n} \mathrm{CNT}-\mathrm{HZ}$ in an air stream $\left(50 \mathrm{~mL} \mathrm{~min}^{-1}\right)$ 


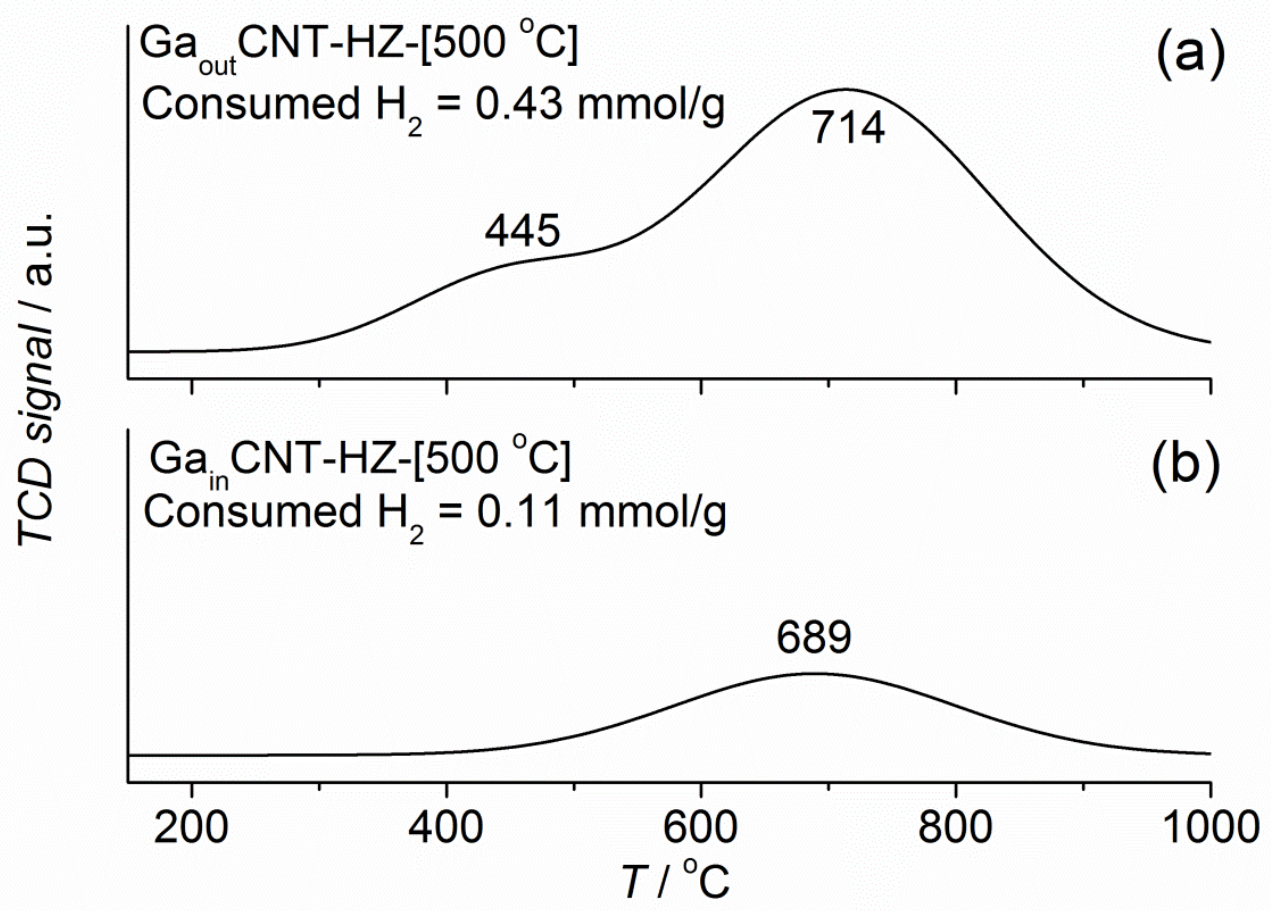

Figure S8. $\mathrm{H}_{2}$-TPR profiles of (a) Ga $\mathrm{Tat}_{\mathrm{ou}} \mathrm{CNT}-\mathrm{HZ}-\left[500{ }^{\circ} \mathrm{C}\right]$ and (b) GainCNT-HZ-[500 $\left.{ }^{\circ} \mathrm{C}\right]$ 


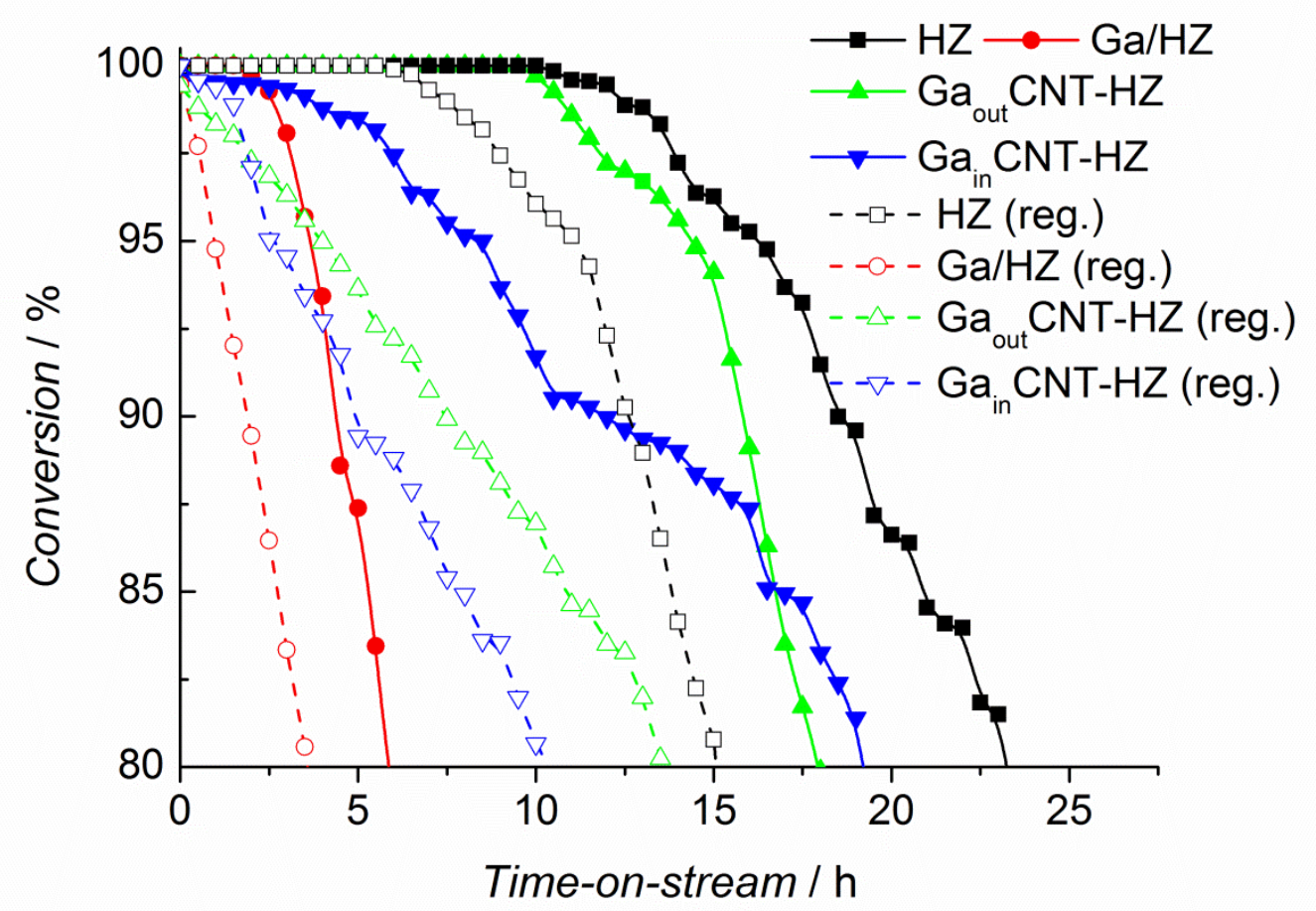

Figure S9. Time course of the conversion of methanol and DME at $500{ }^{\circ} \mathrm{C}$ with $\mathrm{WHSV}=1.3 \mathrm{~h}^{-1}$ for freshly prepared and regenerated catalysts 


\section{References}

1. Nandan, D.; Saxena, S. K.; Viswanadham, N., Synthesis of hierarchical ZSM-5 using glucose as a templating precursor. J. Mater. Chem. A 2014, 2 (4), 1054-1059.

2. Galarneau, A.; Villemot, F.; Rodriguez, J.; Fajula, F.; Coasne, B., Validity of the t-plot Method to Assess Microporosity in Hierarchical Micro/Mesoporous Materials. Langmuir 2014, 30 (44), 13266-13274.

3. Ravel, B.; Newville, M., ATHENA, ARTEMIS, HEPHAESTUS: data analysis for X-ray absorption spectroscopy using IFEFFIT. J. Synchrotron Rad. 2005, 12 (4), 537-541.

4. Epelde, E.; Santos, J. I.; Florian, P.; Aguayo, A. T.; Gayubo, A. G.; Bilbao, J.; Castaño, P., Controlling coke deactivation and cracking selectivity of MFI zeolite by H3PO4 or KOH modification. Appl. Catal. A 2015, 505, 105-115.

5. Abdelrahman, O. A.; Vinter, K. P.; Ren, L.; Xu, D.; Gorte, R. J.; Tsapatsis, M.; Dauenhauer, P. J., Simple quantification of zeolite acid site density by reactive gas chromatography. Catal. Sci. Technol. 2017, 7 (17), 3831-3841. 